\title{
Information entropy risk measure applied to large group decision-making method
}

\author{
Xuan-hua $\mathrm{Xu}^{1} \cdot$ Xintong $\mathrm{Luo}^{1}$
}

Published online: 30 April 2018

(c) The Author(s) 2018

\begin{abstract}
Based on specially significant emergencies, as Tianjin Port, " $8 \cdot 12$ " large fire and explosion accidents and other practical cases, we have a scientific modeling for decision-making process and identify the risk that complex large group decision-makers' preference differences lead to in the process. We propose a new risk measure combined with information entropy theory to measure risk in clustering. Risk due to the complexity of appetite caused in the decision-making process is quantificationally computed, and the size of the risk helps determine the results of the final preference information assembly, whereby the program order. Finally, numerical example illustrates the effectiveness of the method.
\end{abstract}

Keywords Risk measure $\cdot$ Large group · Emergency decision

\section{Introduction}

Major emergencies generally refer to the accidents occurring in a certain time and region and causing great losses of life and property (http://www.chinasafety.gov.cn/2007-04/ 20/content_232858.htm), such as the Tianjin Port " $8 \cdot 12$ " fire and explosion incident. In the study of the risk of major emergencies, the general focus is the risk caused by the emergency disposal taken at the incident scene. When psychological factors are considered to deal with the risk of decision-making according to the prospect theory (Kahneman and Tversky 1979), regret theory (Bell 1982), etc., it means that the impact is taken into account that individual preferences have on the results of selection. This paper considers the risk caused by multiple complex preferences in large group decision-making process. Since the major participant involved in decision-making is mainly the government, this risk is similar to the decision risk faced by government in decision-making process. Bin (2012) analyses the decision-making risk of government investment projects

Communicated by V. Loia.

Xintong Luo

79541466@qq.com

Xuan-hua Xu

xuxh@csu.edu.cn

1 School of Business, Central South University, Changsha 410083, Hunan, People's Republic of China from the perspective of the participants, identifies the risk factors, uses fuzzy clustering method to make the comparison among various risk factors' correlations, and finally establishes an evaluation model to measure the participant risk of government investment projects. And because of the complex preferences, great conflicts are likely to exist among decision-makers' preferences, which are one kind of potential reason of decision risk. Xuanhua et al. (2014) proposes the multi-attribute and multi-stage large group decisionmaking method for preference conflict optimization, which considers phase correction of decision-makers' preferences to optimize the conflict and reduce the risk; Zhanfeng (2012) sets the anti-party system, so the extreme conflict resolution plan is proposed from the macro-level system that helps decision-makers in the mutual discussion to get consistent results. Moreover, different decision-making participants may give different decision-making values. Fasolo and Costa (2014) studies the different representations of numerical and linguistic expressions of decision-making and their effects on decision-making, whereas in the actual decision-making process different forms of decision values may also pose a risk.

Obviously, as for the decision-making of large events, merely participants' complex preferences can lead to a very large number of risk factors. In general, these elements are scientific decision-making process, the clear responsibilities of decision-makers, the rationality of decision-making power distribution, the suitable structure of expert groups, the 
participants' social responsibility, the evaluation forms, the dynamic movement of decision-makers, the conflict caused by the preference and the interpersonal relationship between the participators and so on.

With so many risks, in order to control the adverse effects, we need to have an auxiliary tool to measure and evaluate it. The previous research on risk measurement was almost in the field of finance (Junshan 2007; Chengli and Yan 2014; Ye et al. 2017; Grechuk and Zabarankin 2015), because investment portfolio gains can be directly expressed in numbers to make quantitative calculation of the risk control based on risk measure model. For emergency disposal, investment projects, site selection decisions, etc., all of them involve identifying and analyzing the risk factors as well as rating the risk of the whole decision-making process (Aven 2015). In recent years, the theory of financial risk measurement has gradually matured, and other fields have begun to study the application of risk measurement (Pender et al. 2016). In this paper, we proposed a method of measuring the risk of large group decision-making which focuses on the risk resulting from distribution of the decision-making rights, by calculating the degree of uncertainty with the information entropy theory (Xinlei 2015; Fleischhacker and Fok 2015).

This paper draws lessons from the " $7 \cdot 23$ " Yong-Wen line large-scale railway traffic accident (http://www.chinasafety. gov.cn/newpage/Contents/Channel_21679/2011/1228/2448 74/content_244874.htm), the Tianjin Port "8 · 12" large fire and explosion incident (http://www.chinasafety.gov.cn/ newpage/newfiles/201600812baogao.pdf) and other recent relevant information of emergency disposal. And on the basis of the existing emergency decision-making and risk measurement research, a new large group decision-making method is developed based on risk measurement.

\section{Methodology}

\subsection{Problem description}

According to the emergency disposal parts of the relevant large incident investigation reports in http://www.chinasafet y.gov.cn/newpage/Contents/Channel_21679/2011/1228/24 4874/content_244874.htm and http://www.chinasafety.gov. cn/newpage/newfiles/201600812baogao.pdf, we can simplify the analysis to know that the major emergency decisions can be concluded from three aspects. First, in order to prevent more severe consequences, it is the first step to make a quick emergent decision, such as fire fighting and evacuation of the crowds. At this time, it is mainly the local government and even the relevant departments that directly make emergency decisions in a very limited time, which requires participants' high level of the dynamic decision-making capacity.

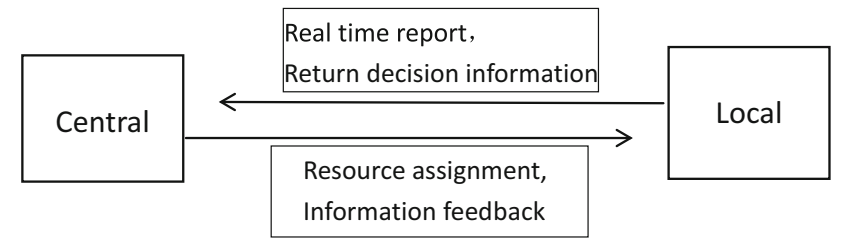

Fig. 1 Major emergencies central-local decision mode diagram

The second is the choice of rescue programs. Since the emergency scene of events may be different, the local government has prepared contingency plans as the alternatives. The third is to make decisions on medical resource scheduling, rescue compensation and other important matters. In addition, in recent years, with the increasing popularity of information technology, network public opinion (Wentao and Dachao 2011) has become a part of emergency decision-making which cannot be ignored. A part of the literature (http://www.chinasafety.gov.cn/newpage/Content s/Channel_21679/2011/1228/244874/content_244874.htm) mentioned that the misleading media reports caused the masses to mistakenly think the rescue has stopped, so the public opinion negatively affects the rescue operations. With the real-time monitoring of public opinion, the state media can announce the latest emergence plans immediately when facing some exceptional cases on the internet.

In the process of decision-making, there is generally a central leadership meeting to listen to the situation report and to make instructions. Then local government immediately establishes the accident rescue headquarters and organizes the relevant departments and experts to make emergency decision. Decision-makers of central departments contact with local headquarters through telephone or video and send representatives to the location to conduct supervision and guidance on local decisions. Therefore, a central-local decision-making model can be established, as shown in Fig. 1.

Assume that the central decision-maker decides the total number of local decision-makers is $m$. And decide the weight range of the local decision-makers in every decision-making process. We try to compute the weight distribution when the risk is the minimum and aggregate the preference information to sort the scheme.

For large group major emergency decision-making, basic symbols are provided as follows:

$\Omega=\left\{e_{1}, e_{2}, \ldots, e_{i}, \ldots, e_{m}\right\}$, represents a collection of $m$ local decision participants, where $m>20$ (Liu et al. 2014);

$A=\left\{a_{1}, a_{2}, \ldots, a_{l}, \ldots, a_{p}\right\}$, represents a collection of $p$ alternative emergency plans;

$C=\left\{c_{1}, c_{2}, \ldots, c_{j}, \ldots, c_{n}\right\}$, represents a collection of $n$ attributes for emergency plans;

$W=\left(w_{1}, w_{2}, \ldots, w_{n}\right)^{\mathrm{T}}$, represents an attribute weight vector, where $\sum_{i=1}^{n} w_{i}=1$. 
$\boldsymbol{\omega}=\left(\omega_{1}, \omega_{2}, \ldots, \omega_{m}\right)^{\mathrm{T}}$, represents weight vector of decision-makers in decision group.

\subsection{Information entropy risk measurement of decision participants' rights distribution}

The risks caused by the decision-makers' right distribution in this paper mainly refer to the situation that the decision results cannot fully express the majority's wishes when all the participants' opinions are assembled.

Suppose that the evaluation value of the alternative $a_{l}$ in attribute $c_{j}$ of the member $e_{i}$ is $d_{l j}^{(i)}$, where $d_{l j}^{(i)} \in[0,1]$, then the preference matrices of $m$ members are given as follows:

$$
D^{(i)}=\left[\begin{array}{lllll}
d_{11}^{(i)} & \cdots & d_{1 j}^{(i)} & \cdots & d_{1 n}^{(i)} \\
\vdots & \ddots & \vdots & \ddots & \vdots \\
d_{l 1}^{(i)} & \cdots & d_{l j}^{(i)} & \cdots & d_{l j}^{(i)} \\
\vdots & \ddots & \vdots & \ddots & \vdots \\
d_{p 1}^{(i)} & \cdots & d_{p j}^{(i)} & \cdots & d_{p n}^{(i)}
\end{array}\right], \quad i=1,2, \ldots, m_{o}
$$

Now the information entropy method is used to measure the risk of the entire decision-making group in the aggregation process, with the attribute weight vector $W$ and the membership weights $\omega$.

(1) As all evaluations of attribute $c_{j}$ are $d_{l j}^{(i)}, i=1, \ldots, m$; $l=1, \ldots, p$, the interval $[0,1]$ is equally divided into $h$ small intervals and the size $h$ is given by the decision-makers. And then the $s$ th small interval is $\left\{\begin{array}{ll}((s-1) / h, s / h], & s>1 \\ {[0,1 / h],} & s=1\end{array}\right.$. According to the membership weights, we can obtain the probability that the $d_{l j}^{(i)}$ falls in the $s$ th interval:

$$
\begin{aligned}
P_{j s}^{l}= & \sum_{i=1}^{m} \omega_{i} S_{i j}^{l}, \quad \text { where } S_{i j}^{l}=\left\{\begin{array}{ll}
0, & d_{l j}^{(i)} \notin((s-1) / h, s / h] \\
1, & d_{l j}^{(i)} \in((s-1) / h, s / h]
\end{array},\right. \\
& j=1,2, \ldots, n
\end{aligned}
$$

(2) In this paper, the average uncertainty degree of evaluation information is expressed by information entropy, and the risk of right distribution when the attribute $c_{j}$ of all schemes' evaluation values is aggregated is calculated as follow:

$E_{j}=-\frac{1}{\ln h} \sum_{l=1}^{p} \sum_{s=1}^{h}\left(P_{j s}^{l} \ln P_{j s}^{l}\right), \quad j=1,2, \ldots, n$

Then the risk vector is $E=\left(E_{1}, E_{2}, \ldots, E_{n}\right)^{\mathrm{T}}$;
(3) Finally, the risk entropy of the decision-making participants resulting from the uneven distribution of rights is obtained:

$$
R=W^{\mathrm{T}} E
$$

\subsection{Decision procedure}

Step 1 The local command center reports the situation of the site to the central departments first. Then the central decisionmaker decides the list of experts $(m>20)$ of each department involved in the decision-making and gives the attributes set $C$ and the attribute weight $W$.

Step 2 Local decision-makers, according to the information given by the central departments, convened above personnel to participate in decision-making. Since the evaluation value of the alternative $a_{l}$ in attribute $c_{j}$ of the member $e_{i}$ is $d_{l j}^{(i)}$, the preference matrices of $m$ members are given as follows:

$$
\begin{aligned}
D^{(i)}= & {\left[\begin{array}{llll}
d_{11}^{(i)} & d_{12}^{(i)} & \cdots & d_{1 n}^{(i)} \\
d_{21}^{(i)} & d_{22}^{(i)} & \cdots & d_{2 n}^{(i)} \\
\cdots & \cdots & \cdots & \cdots \\
d_{p 1}^{(i)} & d_{p 2}^{(i)} & \cdots & d_{p n}^{(i)}
\end{array}\right]=\left(D_{1}^{(i)}, D_{2}^{(i)}, \ldots, D_{n}^{(i)}\right) } \\
& i=1,2, \ldots, m_{o}
\end{aligned}
$$

According to the calculation formula proposed by the literature (Xuanhua et al. 2009), we can obtain the preference convergence degree between the member $e_{i_{1}}$ and the member $e_{i_{3}}$ of the attribute $c_{j}$ :

$r_{j}^{i_{1} i_{2}}\left(D_{j}^{\left(i_{1}\right)}, D_{j}^{\left(i_{2}\right)}\right)=\frac{\left(\left|D_{j}^{\left(i_{1}\right)}-\overline{D_{j}^{\left(i_{1}\right)}}\right|\right)^{\mathrm{T}}\left(\left|D_{j}^{\left(i_{2}\right)}-\overline{D_{j}^{\left(i_{2}\right)}}\right|\right)}{\left\|D_{j}^{\left(i_{1}\right)}-\overline{D_{j}^{\left(i_{1}\right)}}||_{2}\right\| D_{j}^{\left(i_{2}\right)}-\overline{D_{j}^{\left(i_{2}\right)}} \|_{2}}$,

where $\|\bullet\|_{2}$ denotes the 2-norm of the vector, and

$\overline{D_{j}^{(i)}}=\frac{1}{p} \sum_{l=1}^{p} d_{j l}^{(i)}$.

And the preference convergence degree between the member $e_{i_{1}}$ and the member $e_{i_{3}}$ is

$r^{i_{1} i_{2}}=\sum_{j=1}^{n} w_{j} r_{j}^{i_{1} i_{2}}\left(D_{j}^{\left(i_{1}\right)}, D_{j}^{\left(i_{2}\right)}\right)$

Firstly, the members are randomly sorted and the first member is selected to form the aggregation $\Omega_{1}$, which is compared with the left members in pairs to calculate the convergence degree of preferences. And determine appropriate threshold by previous study. Let these members, whose 
degree results are greater than the threshold, join cluster $\Omega_{1}$. After we find all the members to join in $\Omega_{1}$, we select the top number among the remained members according to the previous ranking. Then we continue to compare the top number member with other members which did not join the former cluster $\Omega_{1}$ by the same calculation. Compare the result with the threshold and members having larger results take part in the cluster $\Omega_{2}$. When convergence degrees of preferences between a decision-maker and the rest of the decision-makers are all below the threshold, the separate decision-maker becomes a cluster. The previous steps mentioned in this paragraph should be repeated until all decision-makers can join their appropriate clusters. The decision group is clustered into K clusters, which is $\bar{\Omega}=\left\{\Omega_{1}, \Omega_{2}, \ldots, \Omega_{k}, \ldots\right.$, $\left.\Omega_{K}\right\}$.

Step 3 The previous results are reported back to the central departments, and the central decision-maker gives the weight interval of each expert in each cluster under the uniform standard. In other words, for any cluster $\Omega_{k}$ (whose number of members is denoted as $n_{k}$ ), the infimum set and supremum set of membership weight interval are given:

$$
\begin{aligned}
& \operatorname{Inf}_{k}=\left\{a_{1}^{k}, a_{2}^{k}, \ldots a_{g}^{k}, \ldots, a_{n_{k}}^{k}\right\}, \operatorname{Sup}_{k}=\left\{b_{1}^{k}, b_{2}^{k}, \ldots, b_{g}^{k}, \ldots, b_{n_{k}}^{k}\right\}, \\
& \forall a_{g}^{k} \in[0,1), b_{g}^{k} \in(0,1] \text { and } a_{g}^{k}<b_{g}^{k}, \sum_{g=1}^{n_{k}} a_{g}^{k} \leq 1 \leq \sum_{g=1}^{n_{k}} b_{g}^{k},
\end{aligned}
$$

Then we can randomly obtain the weight $\omega_{g}^{k}, g=$ $1,2, \ldots, q$, of members in cluster $\Omega_{k}$, which meets the condition (1) : $\omega_{g}^{k} \in\left[a_{g}^{k}, b_{g}^{k}\right], g=1,2 \ldots, n_{k}$; condition (2): $\sum_{g=1}^{n_{k}} \omega_{g}^{k}=1$.

Then, the central decision-maker provides the overall weight interval's infimum set Inf $=\left\{a_{1}, a_{2}, \ldots, a_{g}, \ldots, a_{K}\right\}$ and supremum set Sup $=\left\{b_{1}, b_{2}, \ldots b_{g}, \ldots, b_{K}\right\}$ of every cluster, where $\forall a_{g} \in[0,1), b_{g} \in(0,1]$ and $a_{g}<b_{g}$, $\sum_{g=1}^{K} a_{g} \leq 1 \leq \sum_{g=1}^{K} b_{g}$. After aggregating cluster's information into a decision matrix representing each cluster correspondingly, the clusters' weights are randomly selected within the given interval, and that is $\omega_{g}^{\epsilon}\left[a_{g}^{\prime} b_{g}\right], g=$ $1,2, \ldots, K$, where $\sum_{g=1}^{K} \omega_{g}=1$.

Step 4 According to the clustering result of decision group $\bar{\Omega}$, calculate the weights of experts within each cluster. For any cluster $\Omega_{k}$, we use computer to generate a set of random number $X^{k}=\left(x_{1}^{k}, x_{2}^{k}, \ldots, x_{g}^{k}, \ldots, x_{n_{k}}^{k}\right), \forall x_{g}^{k} \in$ $[0,1]$. According to the corresponding weight interval's infimum and supremum, let $y_{g}^{k}=\left(b_{g}^{k}-a_{g}^{k}\right) x_{g}^{k}+a_{g}^{k}, g=$ $1,2, \ldots, n_{k}, \quad Y^{k}=\left\{y_{1}^{k}, y_{2_{1}}^{k}, \ldots, y_{n_{k}}^{k}\right\}$, and normalized $Y^{k}$ get the weight vector $\omega^{k}=\left(\omega_{1}^{k}, \omega_{2}^{k}, \ldots \omega_{n_{k}}^{k}\right)^{\mathrm{T}}$. Obviously it meets the condition (2), and we have to check whether $\boldsymbol{\omega}^{k}$ satisfies the condition(1). If not, we choose the new random numbers again, and continue to find the weight vector that matches the conditions; if satisfies, then take the $\omega^{k}$ as a member weight vector. When obtain an appropriate $\boldsymbol{\omega}^{k}$, we can use the right distribution risk model of the decision-making participant proposed in this paper to calculate the risk under this weight vector:

(1) we have already obtained $K$ clusters, and all the members of each cluster are in the corresponding set $\mathrm{I}_{\Omega_{k}}=$ $\left\{e_{1 k}, e_{2 k}, \mathrm{~K}, e_{n k}\right\}$, then the Cluster $\Omega_{k}$ 's decision matrix for $n$ attributes of $m$ alternatives is as follows:

$$
D^{i k}=\left[\begin{array}{cccc}
d_{11}^{i k} & d_{12}^{i k} & \cdots & d_{1 n}^{i k} \\
d_{21}^{i k} & d_{22}^{i k} & \cdots & d_{2 n}^{i k} \\
\cdots & \cdots & \cdots & \cdots \\
d_{p 1}^{i k} & d_{p 2}^{i k} & \cdots & d_{p n}^{i k}
\end{array}\right], \quad i=1,2, \ldots, n_{k}
$$

(2) Members in cluster $\Omega_{k}$ provide the evaluation value $d_{l j}^{i k}, i=1, \ldots, n_{k}$. for the alternative $a_{l}^{\prime}$ s attribute $c_{j}$. According to formula (1), calculate the probability distributions that the $d_{l j}^{i k}$ falls in the different intervals. Then, use the formula (2) to obtain the risk generated by the distributions mentioned above. Finally, we can get the whole risk entropy value by formula (3).

Repeat choosing random numbers for appropriate times to get teams of the weight vector, and each team's risk entropy value is calculated. Then select the optimal weight vector $\omega_{*}^{k}$ corresponding to the smallest risk entropy and use weighted average operator (Yager and Alajlan 2016) to gather decision information in cluster $\Omega_{k}$. Then obtain $D_{\Omega_{k}}=\sum_{g=1}^{n_{k}} \omega_{* g}^{k} D\left(i_{g}\right)$. Apply the above method to each gathering processing to get each cluster's gathering results with the minimum risk entropy value, which is equal to obtaining decision preference matrix of the number of gathering members $\mathrm{K}$.

Step 5 In each given cluster's weight interval, we select a random number to be combined, and then normalize each group of random numbers. We select multiple weight combinations that satisfy the limit interval, measure the risk of aggregating process in turn, and choose the weight vector $\omega^{*}=\left(\omega_{1}^{*}, \omega_{2}^{*}, \ldots \omega_{K}^{*}\right)^{\mathrm{T}}$ when the risk is the smallest, and that is to get decision-making preference matrix that aggregates all the information $D=\sum_{k=1}^{K} \omega_{k}^{*} D_{\Omega_{k}}$. Finally, according to the given attribute weight $\mathbf{W}$, calculate the final score $\mathbf{F}=\mathbf{W}^{\mathrm{T}} D$ of all programs, and sort the scores by number, which should be sent to the central decision-makers for approval and implementation. 
Table 1 Personnel scheduling scheme

\begin{tabular}{lcc}
\hline Department & Decision & Scene rescue \\
\hline Administration of work safety & 7 & 224 \\
Department of public health & 5 & 150 \\
Environmental Protection Department & 5 & 123 \\
The Meteorological Department & 3 & 57 \\
The people's Liberation Army & 4 & 1353 \\
The armed police forces & 3 & 986 \\
Firefighting force & 5 & 2124 \\
Others (Explosion-proof, & 8 & 534 \\
anti-chemical, epidemic prevention, & & \\
etc.) & & 5551 \\
Total & 40 &
\end{tabular}

\section{Numerical examples}

After receiving the call that a warehouse in the storage of dangerous goods broke out of fire, the Public Security Bureau 110 command center quickly sent the fire brigade to put out the fire and evacuate the crowds. Because of the rapid spread of fire and explosion, casualties and property losses continued to increase, reaching the major disaster level. The command center immediately contacted the central departments to report details of the incident.

Step 1 The central departments set up a decision-making group with four members, which led by the leader of highest level in the group to make decisions on this major incident and schedule the relevant departments to the scene to rescue personnel and make decisions (Table 1).

For 4 known different evacuation routes $A=\left\{a_{1}, a_{2}\right.$, $\left.a_{3}, a_{4}\right\}$, the central decision-making group gives five attributes which should be included in the reference based on the feedback from the site: $c_{1}$ : terrain convenience, $c_{2}$ : the suitable degree of local weather, $c_{3}$ : the intact degree of medical facilities, $c_{4}$ : the impossibility of secondary disasters, $c_{5}$ : adequacy of material, that is $C=\left\{c_{1}, c_{2}, c_{3}, c_{4}, c_{5}\right\}$. Each member of the central group gives the recommended value of the attribute weight and then gets averages. After that the weight of each attribute of the scheme is obtained as shown in Table 2 . The central decision-making group sent 40 decisionmakers $\Omega=\left\{e_{1}, e_{2}, \ldots, e_{40}\right\}$ to constitute large groups of decision-making.

Step 2 Upon receiving the notice from the central government, the local command team contacted the decisionmaking groups to make quick evaluation on the five attributes of the four contingency plans according to the situation on site. The evaluation results are shown in Appendix 1. The degree of convergence among the decision-making preference matrices is calculated by the formula (4) and (5), and the decision-maker whose clustering degree is above the given
Table 2 Attribute weight assignment

\begin{tabular}{llllll}
\hline Attribute code & $c_{1}$ & $c_{2}$ & $c_{3}$ & $c_{4}$ & $c_{5}$ \\
\hline Member1 & 0.25 & 0.12 & 0.30 & 0.13 & 0.20 \\
Member2 & 0.23 & 0.15 & 0.32 & 0.05 & 0.20 \\
Member3 & 0.30 & 0.12 & 0.25 & 0.05 & 0.23 \\
Member4 & 0.20 & 0.20 & 0.33 & 0.13 & 0.24 \\
Weight & 0.245 & 0.147 & 0.300 & 0.091 & 0.217 \\
\hline
\end{tabular}

threshold $\gamma=0.8$ (Xuanhua et al. 2009) is clustered. In this paper, the degree of convergence between decision-maker $e_{1}$ 's and $e_{2}$ 's decision matrices is taken as an example (calculated by using the MATLAB programming).

The two matrices are as follows:

$$
\begin{aligned}
& D^{(1)}=\left[\begin{array}{lllll}
0.4 & 0.5 & 0.7 & 0.1 & 0.9 \\
0.6 & 0.5 & 0.1 & 0.7 & 0.2 \\
0.5 & 0.9 & 0.3 & 0.2 & 0.3 \\
0.4 & 0.5 & 0.3 & 0.6 & 0.2
\end{array}\right] \\
& =\left(D_{1}^{(1)}, D_{2}^{(1)}, D_{3}^{(1)}, D_{4}^{(1)}, D_{5}^{(1)}\right) \text {, } \\
& D^{(2)}=\left[\begin{array}{lllll}
0.7 & 0.5 & 0.3 & 0.1 & 0.8 \\
0.6 & 0.4 & 0.2 & 0.7 & 0.6 \\
0.5 & 0.9 & 0.5 & 0.2 & 0.3 \\
0.4 & 0.5 & 0.1 & 0.6 & 0.2
\end{array}\right] \\
& =\left(D_{1}^{(2)}, D_{2}^{(2)}, D_{3}^{(2)}, D_{4}^{(2)}, D_{5}^{(2)}\right) \text {. }
\end{aligned}
$$

The preference coherence degree of decision-maker $e_{1}$ and $e_{2}$ is calculated for each attribute separately:

$$
\begin{aligned}
r_{j}^{12}\left(D_{j}^{(1)}, D_{j}^{(2)}\right) & \left(\left|D_{j}^{(1)}-\overline{D_{j}^{(1)}}\right|\right)^{\mathrm{T}}\left(\left|D_{j}^{(2)}-\overline{D_{j}^{(2)}}\right|\right) \\
= & \frac{\left\|D_{j}^{(1)}-\overline{D_{j}^{(1)}}\right\|_{2}\left\|D_{j}^{(2)}-\overline{D_{j}^{(2)}}\right\|_{2}}{\|}, j=1,2, \ldots 5,
\end{aligned}
$$

where $\overline{D_{j}^{(1)}}=\frac{1}{4} \sum_{l=1}^{4} d_{j l}^{(1)}, \overline{D_{j}^{(2)}}=\frac{1}{4} \sum_{l=1}^{4} d_{j l}^{(2)}$. The results are shown in Table 3.

According to the attribute weight assignment given by the central group, the total degree of the two decision-makers can be obtained:

Table 3 The degree between $e_{1}$ and $e_{2}$ on each attribute

\begin{tabular}{llllll}
\hline Attribute code & $c_{1}$ & $c_{2}$ & $c_{3}$ & $c_{4}$ & $c_{5}$ \\
\hline Degree & 0.8086 & 0.9771 & 0.3684 & 1 & 0.9349 \\
\hline
\end{tabular}


Table 4 Decision-makers clustering results

\begin{tabular}{lcll}
\hline Cluster code & Number of members & Detailed list & Consistency index \\
\hline$\Omega_{1}$ & 11 & $e_{1}, e_{5}, e_{10}, e_{12}, e_{13}, e_{22}, e_{31}, e_{32}, e_{36}, e_{37}, e_{38}$ & 0.8521 \\
$\Omega_{2}$ & 5 & $e_{2}, e_{9}, e_{18}, e_{21}, e_{25}$ & 0.8925 \\
$\Omega_{3}$ & 7 & $e_{3}, e_{7}, e_{11}, e_{17}, e_{27}, e_{30}, e_{35}$ & 0.9335 \\
$\Omega_{4}$ & 8 & $e_{4}, e_{15}, e_{19}, e_{28}, e_{33}, e_{34}, e_{39}, e_{40}$ & 0.9290 \\
$\Omega_{5}$ & 5 & $e_{6}, e_{14}, e_{20}, e_{23}, e_{24}$ & 0.8539 \\
$\Omega_{6}$ & 4 & $e_{8}, e_{16}, e_{26}, e_{29}$ & 0.9486
\end{tabular}

Table 5 Cluster weight interval

\begin{tabular}{lllllll}
\hline Cluster code & $\Omega_{1}$ & $\Omega_{2}$ & $\Omega_{3}$ & $\Omega_{4}$ & $\Omega_{5}$ & $\Omega_{6}$ \\
\hline Weight interval & {$[0.3,0.4]$} & {$[0.1,0.2]$} & {$[0.2,0.3]$} & {$[0.2,0.3]$} & {$[0,0.1]$} & {$[0,0.1]$} \\
\hline
\end{tabular}

Table 6 When $h=5$, the best weighting result for each cluster

\begin{tabular}{llr}
\hline Cluster & Weight vector & Risk value \\
\hline$\Omega_{1}$ & $(0.0912,0.0730,0.0311,0.0745,0.0880,0.0981,0.0984,0.0950,0.0655,0.0981,0.1872)^{\mathrm{T}}$ & 0.5070 \\
$\Omega_{2}$ & $(0.5576,0.1075,0.1976,0.0601,0.0772)^{\mathrm{T}}$ & 0.2368 \\
$\Omega_{3}$ & $(0.0881,0.0681,0.0938,0.0227,0.1251,0.2974,0.3047)^{\mathrm{T}}$ & 0.9813 \\
$\Omega_{4}$ & $(0.2456,0.0052,0.1706,0.1188,0.3008,0.0123,0.0115,0.1352)^{\mathrm{T}}$ & 0.5000 \\
$\Omega_{5}$ & $(0.1371,0.0493,0.5811,0.0293,0.2033)^{\mathrm{T}}$ & 0.5215 \\
$\Omega_{6}$ & $(0.0787,0.8617,0.0181,0.0415)^{\mathrm{T}}$ & 0.0702 \\
\hline
\end{tabular}

Table 7 When $h=10$, the best weighting result for each cluster

\begin{tabular}{lll}
\hline Cluster & Weight vector & Risk value \\
\hline$\Omega_{1}$ & $(0.0887,0.0921,0.0847,0.0500,0.0776,0.0980,0.0972,0.0502,0.0987,0.0735,0.1894)^{\mathrm{T}}$ & 0.5708 \\
$\Omega_{2}$ & $(0.5520,0.1010,0.1273,0.0386,0.1811)^{\mathrm{T}}$ & 0.7886 \\
$\Omega_{3}$ & $(0.0294,0.0889,0.0616,0.0821,0.1795,0.2150,0.3434)^{\mathrm{T}}$ & 0.7008 \\
$\Omega_{4}$ & $(0.2106,0.0032,0.1252,0.1849,0.3019,0.0271,0.0322,0.1148)^{\mathrm{T}}$ & 0.6441 \\
$\Omega_{5}$ & $(0.1051,0.0085,0.5161,0.1004,0.2699)^{\mathrm{T}}$ & 0.8766 \\
$\Omega_{6}$ & $(0.0614,0.8270,0.0452,0.0664)^{\mathrm{T}}$ & 0.1656 \\
\hline
\end{tabular}

$$
\begin{aligned}
r^{12}= & 0.245 \times 0.8086+0.147 \times 0.9771+0.301 \times 0.3684 \\
& +0.091 \times 1+0.216 \times 0.9349=0.7456
\end{aligned}
$$

When $\gamma=0.8$, we have calculation on each two decisionmakers together and cluster decision-makers whose results are greater than 0.8 . The results are shown in Table 4.

Step 3 The results will be reported back to the central decision-making team. Given that the central decisionmakers give the interval number $h=5$ and $h=10$, respectively, each weight interval is gathered for internal decision-makers of each cluster. It should be ensured that all members' weights in a given range can be added to 1 . The interval numbers are shown in Appendix 2.

The central decision group assigned the weight interval for each cluster according to the number of members, as shown in Table 5.
Step 4 Randomly select the numbers in the interval given in Appendix 2 and normalize the weight of each decisionmaker to meet the conditions. Then measure the risk of cluster under the weight distribution and choose 10 effective risk entropy results to make comparisons. When the risk entropy is minimum, choose the weight distribution results for real clustering. Tables 6 and 7 show the best weight distribution of each cluster. The programming results of MATLAB are shown in Tables 8 and 9.

Step 5 Make a random selection from weight interval in Table 5 and ensure that the normalized weights are obtained in the weight range. Then make effective operations for over 10 times. Calculation results of risk level are shown in Tables 10 and 11 . We choose a set of weights with the least risk, when $h=5, \omega^{*}=(0.3704,0.1017,0.2125,0.2924$, $0.0055,0.0175)^{\mathrm{T}}$ and $h=10, \omega^{*}=(0.3249,0.1702$, 
Table 8 When $h=5$, the clustering result of each cluster

\begin{tabular}{|c|c|c|}
\hline Cluster & Clusteri & ig results \\
\hline$\Omega_{1}$ & $D_{\Omega_{1}}=$ & {$\left[\begin{array}{llllll}0.4183 & 0.4906 & 0.6100 & 0.1479 & 0.8797 \\
0.6031 & 0.5144 & 0.1126 & 0.6970 & 0.2171 \\
0.4922 & 0.8489 & 0.3000 & 0.2095 & 0.3100 \\
0.4000 & 0.4927 & 0.3000 & 0.5804 & 0.2470\end{array}\right]$} \\
\hline$\Omega_{2}$ & $D_{\Omega_{2}}=$ & $\left.\begin{array}{llllll}0.6450 & 0.4893 & 0.3000 & 0.1425 & 0.7678 \\
0.6000 & 0.3802 & 0.1832 & 0.7000 & 0.5708 \\
0.5013 & 0.8725 & 0.4893 & 0.1725 & 0.3000 \\
0.4000 & 0.5000 & 0.1000 & 0.6000 & 0.2000\end{array}\right]$ \\
\hline$\Omega_{3}$ & $D_{\Omega_{3}}=$ & {$\left[\begin{array}{llllll}0.6137 & 0.2000 & 0.2634 & 0.3074 & 0.6297 \\
0.8611 & 0.1726 & 0.5225 & 0.8694 & 0.4204 \\
0.4702 & 0.8374 & 0.4695 & 0.1125 & 0.5999 \\
0.4698 & 0.1000 & 0.5931 & 0.1305 & 0.1907\end{array}\right]$} \\
\hline$\Omega_{4}$ & $D_{\Omega_{4}}=$ & {$\left[\begin{array}{lllll}0.6905 & 0.7503 & 0.2949 & 0.6235 & 0.3395 \\
0.6429 & 0.1971 & 0.5936 & 0.5337 & 0.2000 \\
0.3067 & 0.2803 & 0.4120 & 0.1699 & 0.5473 \\
0.6302 & 0.3238 & 0.7100 & 0.6005 & 0.2894\end{array}\right]$} \\
\hline$\Omega_{5}$ & $D_{\Omega_{5}}=$ & {$\left[\begin{array}{llllll}0.2029 & 0.7989 & 0.3838 & 0.4419 & 0.2279 \\
0.7370 & 0.6677 & 0.5586 & 0.1784 & 0.6163 \\
0.4838 & 0.4050 & 0.5030 & 0.4620 & 0.6635 \\
0.2000 & 0.1407 & 0.2366 & 0.1000 & 0.6594\end{array}\right]$} \\
\hline$\Omega_{6}$ & $D_{\Omega_{6}}=$ & $\left.\begin{array}{llllll}0.4805 & 0.4236 & 0.7746 & 0.2236 & 0.3847 \\
0.6983 & 0.5291 & 0.8843 & 0.1060 & 0.1315 \\
0.5959 & 0.1296 & 0.3157 & 0.3157 & 0.6157 \\
0.7587 & 0.1921 & 0.5607 & 0.8370 & 0.4236\end{array}\right]$ \\
\hline
\end{tabular}

Table 9 When $h=10$, the clustering result of each cluster

\begin{tabular}{|c|c|c|}
\hline Cluster & Clusteri & g results \\
\hline$\Omega_{1}$ & $D_{\Omega_{1}}=$ & {$\left[\begin{array}{llllll}0.4100 & 0.4935 & 0.6196 & 0.1436 & 0.8793 \\
0.5970 & 0.5049 & 0.1135 & 0.6916 & 0.2190 \\
0.4874 & 0.8496 & 0.2976 & 0.2050 & 0.3113 \\
0.4000 & 0.4908 & 0.3000 & 0.5806 & 0.2390\end{array}\right]$} \\
\hline$\Omega_{2}$ & $D_{\Omega_{2}}=$ & {$\left[\begin{array}{llllll}0.6451 & 0.4899 & 0.3000 & 0.1306 & 0.7697 \\
0.6000 & 0.3873 & 0.1860 & 0.7000 & 0.5617 \\
0.4845 & 0.8759 & 0.4899 & 0.1692 & 0.3000 \\
0.4000 & 0.5000 & 0.1000 & 0.6000 & 0.2000\end{array}\right]$} \\
\hline$\Omega_{3}$ & $D_{\Omega_{3}}=$ & {$\left[\begin{array}{llllll}0.6047 & 0.2000 & 0.2696 & 0.3104 & 0.6214 \\
0.8613 & 0.1774 & 0.5272 & 0.8656 & 0.4194 \\
0.4785 & 0.8359 & 0.4656 & 0.1179 & 0.5999 \\
0.4547 & 0.1000 & 0.5910 & 0.1343 & 0.1902\end{array}\right]$} \\
\hline$\Omega_{4}$ & $D_{\Omega_{4}}=$ & $\begin{array}{llllll}0.7417 & 0.7881 & 0.2725 & 0.6874 & 0.2548 \\
0.6468 & 0.1342 & 0.6743 & 0.5104 & 0.2000 \\
0.2874 & 0.1626 & 0.4447 & 0.1698 & 0.5874 \\
0.6564 & 0.3000 & 0.7574 & 0.6003 & 0.3027\end{array}$ \\
\hline$\Omega_{5}$ & $D_{\Omega_{5}}=$ & $\begin{array}{llllll}0.2100 & 0.7863 & 0.3968 & 0.4484 & 0.2434 \\
0.7475 & 0.6936 & 0.5689 & 0.1786 & 0.6032 \\
0.4968 & 0.4008 & 0.5100 & 0.4604 & 0.6698 \\
0.2000 & 0.1540 & 0.2302 & 0.1000 & 0.6460\end{array}$ \\
\hline$\Omega_{6}$ & $D_{\Omega_{6}}=$ & $\begin{array}{llllll}0.4882 & 0.4184 & 0.7771 & 0.2184 & 0.3949 \\
0.6859 & 0.5224 & 0.8877 & 0.1112 & 0.1246 \\
0.5934 & 0.1296 & 0.3123 & 0.3123 & 0.6123 \\
0.7743 & 0.1939 & 0.5693 & 0.8509 & 0.4184\end{array}$ \\
\hline
\end{tabular}

$0.2227,0.2576,0.0145,0.0101)^{\mathrm{T}}$. We get the final decision evaluation matrix and calculate the final value of each scheme
Table 10 When $h=5$, each cluster weight distribution and its risk

\begin{tabular}{ll}
\hline$W$ & $R$ \\
\hline$(0.3167,0.1085,0.2063,0.2099,0.0105,0.1481)^{\mathrm{T}}$ & 1.5208 \\
$(0.3204,0.1732,0.2338,0.2094,0.0204,0.0428)^{\mathrm{T}}$ & 1.4521 \\
$(0.3337,0.1588,0.2111,0.2681,0.0263,0.0021)^{\mathrm{T}}$ & 1.4291 \\
$(0.3704,0.1017,0.2125,0.2924,0.0055,0.0175)^{\mathrm{T}}$ & 1.4084 \\
$(0.3063,0.1309,0.2165,0.2079,0.0663,0.0721)^{\mathrm{T}}$ & 1.5405 \\
$(0.3089,0.1408,0.2378,0.2165,0.0692,0.0268)^{\mathrm{T}}$ & 1.4998 \\
$(0.3212,0.1208,0.2747,0.2302,0.0256,0.0275)^{\mathrm{T}}$ & 1.4415 \\
$(0.3689,0.1026,0.2643,0.2223,0.0139,0.0280)^{\mathrm{T}}$ & 1.4109 \\
$(0.3291,0.1386,0.2734,0.2027,0.0179,0.0383)^{\mathrm{T}}$ & 1.4329 \\
$(0.3328,0.1324,0.2353,0.2556,0.0287,0.0152)^{\mathrm{T}}$ & 1.4447 \\
\hline
\end{tabular}

Table 11 When $h=10$, each cluster weight distribution and its risk

\begin{tabular}{ll}
\hline$W$ & $R$ \\
\hline$(0.3045,0.1801,0.2401,0.2128,0.0613,0.0012)^{\mathrm{T}}$ & 2.1749 \\
$(0.3249,0.1702,0.2227,0.2576,0.0145,0.0101)^{\mathrm{T}}$ & 2.0957 \\
$(0.3435,0.1654,0.2064,0.2122,0.0259,0.0466)^{\mathrm{T}}$ & 2.1593 \\
$(0.3166,0.1243,0.2190,0.2426,0.0398,0.0577)^{\mathrm{T}}$ & 2.2512 \\
$(0.3101,0.1979,0.2134,0.2166,0.0051,0.0569)^{\mathrm{T}}$ & 2.1102 \\
$(0.3159,0.1150,0.2498,0.2360,0.0348,0.0485)^{\mathrm{T}}$ & 2.1988 \\
$(0.3009,0.1341,0.2152,0.2001,0.0992,0.0505)^{\mathrm{T}}$ & 2.3402 \\
$(0.3539,0.1678,0.2067,0.2218,0.0205,0.0292)^{\mathrm{T}}$ & 2.1161 \\
$(0.3449,0.1030,0.2685,0.2349,0.0001,0.0486)^{\mathrm{T}}$ & 2.0969 \\
$(0.3034,0.1580,0.2530,0.2033,0.0473,0.0350)^{\mathrm{T}}$ & 2.1730 \\
\hline
\end{tabular}

according to the attribute weight in Table 2. The evaluation values are shown in Tables 12 and 13.

Finally both of the two cases' ranking results are: $a_{1}>$ $a_{2}>a_{3}>a_{4}$, which are conveyed to the central decisionmaking group to determine the final program selection.

\section{Conclusion}

This paper provides a method of multi-attribute emergency decision-making for large group, calculates the risk in the decision-making by risk measurement proposed, and reduces the risk of the process of clustering, which makes the conclusion better reflect the views of decision-makers. Through the calculation of the preference convergence and the risk of the decision-maker's rights distribution, the risk caused by the preference difference and the distribution of rights are considered. When processing vast amounts of information, we often cannot use a precise number to represent all of our views. The fuzzy interval uses high-speed operation of the computer to find the result consistent with the demand and reflecting the views of most people. In fact, expansion research can be made on central decision-makers, for example, with large data method a more appropriate num- 
Table 12 When $h=5$, the final evaluation result

Table 13 When $h=10$, the final evaluation result

\begin{tabular}{lllllll}
\hline Alternatives/attributes & $c_{1}$ & $c_{2}$ & $c_{3}$ & $c_{4}$ & $c_{5}$ & Final evaluation \\
\hline$a_{1}$ & 0.5624 & 0.5052 & 0.4143 & 0.3233 & 0.6450 & 0.5055 \\
$a_{2}$ & 0.6716 & 0.3364 & 0.3635 & 0.6730 & 0.2920 & 0.4477 \\
$a_{3}$ & 0.4360 & 0.6676 & 0.3894 & 0.1768 & 0.4473 & 0.4349 \\
$a_{4}$ & 0.4873 & 0.3534 & 0.4661 & 0.4945 & 0.2480 & 0.4102 \\
\hline
\end{tabular}

\begin{tabular}{lllllll}
\hline Alternatives/attributes & $c_{1}$ & $c_{2}$ & $c_{3}$ & $c_{4}$ & $c_{5}$ & Final evaluation \\
\hline$a_{1}$ & 0.5605 & 0.4928 & 0.3740 & 0.3143 & 0.5997 & 0.4805 \\
$a_{2}$ & 0.6500 & 0.2999 & 0.3737 & 0.6493 & 0.3142 & 0.4428 \\
$a_{3}$ & 0.4192 & 0.6347 & 0.3996 & 0.1684 & 0.4432 & 0.4273 \\
$a_{4}$ & 0.4665 & 0.3323 & 0.4409 & 0.4663 & 0.2438 & 0.3910
\end{tabular}

ber of participants and distribution can be selected. Actually the number of people involved in decision-making can be dynamic. The method presented in this paper can deal with the situation of dynamic large groups, and the risk control of dynamic decision participants can be further studied on the basis of this paper.

There are also shortcomings. For instance, when there is too much limits of selection of the random number, it is difficult to find the weights that can fully meet the conditions from the random numbers in the selected range; with less range limits of random number, the risk level changes greatly. We can consider using numerical approximation and other methods to set a risk threshold, which can solve the appropriate weight interval until the interval's corresponding risk value is below this threshold.

Acknowledgements The authors would like to thank the editors and anonymous reviewers for their insightful comments and suggestions. This research is supported by the grant from National Natural Science Foundation in China (Nos. 71671189, 71790615, 71431006), Innovation-driven Program of Central South University (2015CX010), Mobile E-business Collaborative Innovation Center of in Hunan Province and Key Laboratory of Hunan Province for mobile business intelligence, Key program for Financial Research Institute Foundation of Wenzhou University.

\section{Compliance with ethical standards}

Conflict of interest We declare that we do not have any commercial or associative interest that represents a conflict of interest in connection with the work submitted.

Open Access This article is distributed under the terms of the Creative Commons Attribution 4.0 International License (http://creativecomm ons.org/licenses/by/4.0/), which permits unrestricted use, distribution, and reproduction in any medium, provided you give appropriate credit to the original author(s) and the source, provide a link to the Creative Commons license, and indicate if changes were made.

\section{Appendix 1: Group decision evaluation}

See Table 14.
Table 14 Assessment data for 40 decision makers

\begin{tabular}{|c|c|c|c|c|c|c|}
\hline \multicolumn{2}{|c|}{ Member/alternative } & \multicolumn{5}{|c|}{ Attribute } \\
\hline & & $c_{1}$ & $c_{2}$ & $c_{3}$ & $c_{4}$ & $c_{5}$ \\
\hline \multirow[t]{4}{*}{$e_{1}$} & $l_{1}$ & 0.4 & 0.5 & 0.7 & 0.1 & 0.9 \\
\hline & $l_{2}$ & 0.6 & 0.5 & 0.1 & 0.7 & 0.2 \\
\hline & $l_{3}$ & 0.5 & 0.9 & 0.3 & 0.2 & 0.3 \\
\hline & $l_{4}$ & 0.4 & 0.5 & 0.3 & 0.6 & 0.2 \\
\hline \multirow[t]{4}{*}{$e_{2}$} & $l_{1}$ & 0.7 & 0.5 & 0.3 & 0.1 & 0.8 \\
\hline & $l_{2}$ & 0.6 & 0.4 & 0.2 & 0.7 & 0.6 \\
\hline & $l_{3}$ & 0.5 & 0.9 & 0.5 & 0.2 & 0.3 \\
\hline & $l_{4}$ & 0.4 & 0.5 & 0.1 & 0.6 & 0.2 \\
\hline \multirow[t]{4}{*}{$e_{3}$} & $l_{1}$ & 0.6 & 0.2 & 0.3 & 0.3 & 0.6 \\
\hline & $l_{2}$ & 0.9 & 0.2 & 0.6 & 0.9 & 0.4 \\
\hline & $l_{3}$ & 0.5 & 0.9 & 0.5 & 0.1 & 0.6 \\
\hline & $l_{4}$ & 0.5 & 0.1 & 0.6 & 0.1 & 0.1 \\
\hline \multirow[t]{4}{*}{$e_{4}$} & $l_{1}$ & 0.7 & 0.8 & 0.3 & 0.7 & 0.3 \\
\hline & $l_{2}$ & 0.7 & 0.1 & 0.7 & 0.5 & 0.2 \\
\hline & $l_{3}$ & 0.3 & 0.1 & 0.5 & 0.2 & 0.6 \\
\hline & $l_{4}$ & 0.7 & 0.3 & 0.8 & 0.6 & 0.3 \\
\hline \multirow[t]{4}{*}{$e_{5}$} & $l_{1}$ & 0.5 & 0.5 & 0.7 & 0.1 & 0.9 \\
\hline & $l_{2}$ & 0.6 & 0.4 & 0.1 & 0.7 & 0.3 \\
\hline & $l_{3}$ & 0.5 & 0.9 & 0.3 & 0.2 & 0.3 \\
\hline & $l_{4}$ & 0.4 & 0.4 & 0.3 & 0.6 & 0.3 \\
\hline \multirow[t]{4}{*}{$e_{6}$} & $l_{1}$ & 0.2 & 0.7 & 0.5 & 0.5 & 0.1 \\
\hline & $l_{2}$ & 0.8 & 0.9 & 0.7 & 0.1 & 0.5 \\
\hline & $l_{3}$ & 0.6 & 0.4 & 0.5 & 0.5 & 0.8 \\
\hline & $l_{4}$ & 0.2 & 0.1 & 0.1 & 0.1 & 0.7 \\
\hline \multirow[t]{4}{*}{$e_{7}$} & $l_{1}$ & 0.4 & 0.2 & 0.2 & 0.1 & 0.6 \\
\hline & $l_{2}$ & 0.8 & 0.2 & 0.6 & 0.9 & 0.4 \\
\hline & $l_{3}$ & 0.5 & 0.9 & 0.5 & 0.1 & 0.6 \\
\hline & $l_{4}$ & 0.4 & 0.1 & 0.5 & 0.1 & 0.1 \\
\hline
\end{tabular}


Table 14 continued

Member/alternative Attribute

\begin{tabular}{ccccccc} 
& & $c_{1}$ & $c_{2}$ & $c_{3}$ & $c_{4}$ & $c_{5}$ \\
\hline$e_{8}$ & $l_{1}$ & 0.5 & 0.4 & 0.8 & 0.2 & 0.4
\end{tabular}

$\begin{array}{llllll}l_{2} & 0.6 & 0.5 & 0.9 & 0.2 & 0.1\end{array}$

$\begin{array}{llllll}l_{3} & 0.6 & 0.2 & 0.3 & 0.3 & 0.6 \\ l_{4} & 0.9 & 0.2 & 0.6 & 0.9 & 0.4\end{array}$

$e_{9} \quad l_{1}$

$l_{2}$

$l_{3}$

$e_{10} \quad l_{1}$

$l_{2}$

$l_{3}$

$e_{11} \quad l_{1}$

$l_{2}$
$l_{3}$

$e_{12} \quad l_{1}$

$l_{2}$
$l_{3}$

$\begin{array}{ll} & \\ e_{13} & l_{4} \\ l_{1}\end{array}$

$l_{2}$

$l_{3}$

$e_{14} \quad l_{1}$

$l_{2}$

$l_{3}$

$e_{15} \quad l_{1}$

$l_{2}$

$l_{3}$

$\begin{array}{ll} & \\ e_{16} & l_{4} \\ l_{1}\end{array}$

$l_{2}$

$l_{3}$
$l_{4}$

$e_{17} \quad l_{1}$

$l_{2}$

$l_{3}$

$l_{4}$

$e_{18} \quad l_{1}$

$l_{2}$

$l_{3}$

$\begin{array}{ll} & l_{4} \\ e_{19} & l_{1}\end{array}$

$l_{2}$

$\begin{array}{lllll}0.5 & 0.4 & 0.3 & 0.2 & 0.5\end{array}$

$\begin{array}{llllll}0.6 & 0.4 & 0.1 & 0.7 & 0.4\end{array}$

$\begin{array}{lllll}0.4 & 0.7 & 0.4 & 0.2 & 0.3\end{array}$

$\begin{array}{llllll}0.4 & 0.5 & 0.1 & 0.6 & 0.2\end{array}$

$\begin{array}{llllll}0.3 & 0.5 & 0.7 & 0.1 & 0.8\end{array}$

$\begin{array}{lllll}0.4 & 0.5 & 0.2 & 0.6 & 0.2\end{array}$

$0.5 \quad 0.8$

$0.4 \quad 0.5$

$0.7 \quad 0.2$

$0.9 \quad 0$.

$0.5 \quad 0.9$

$0.6 \quad 0.1$

$\begin{array}{lllll}0.4 & 0.4 & 0.2 & 0.1 & 0.8\end{array}$

$\begin{array}{llllll}0.6 & 0.5 & 0.1 & 0.7 & 0.2\end{array}$

$\begin{array}{lll}0.6 & 0.9 & 0.3\end{array}$

$\begin{array}{lll}0.4 & 0.5 & 0.3\end{array}$

$\begin{array}{lll}0.3 & 0.7 & 0.6\end{array}$

$\begin{array}{lll}0.6 & 0.5 & 0.1\end{array}$

$0.4 \quad 0.8$

$0.4 \quad 0.5$

0.3

0.2

0.7

0.

0.

$0.4 \quad 0.7$

$0.7 \quad 0$

$0.3 \quad 0.1$

$0.7 \quad 0.3$

$0.5 \quad 0.4$

$0.7 \quad 0.5$

$0.6 \quad 0.1$

$0.8 \quad 0.2$

$0.6 \quad 0.2$

$0.8 \quad 0.2$

$0.5 \quad 0.8$

$0.4 \quad 0.1$

$0.6 \quad 0.5$

$0.6 \quad 0.3$

$0.6 \quad 0.9$

$0.4 \quad 0.5$

0.7

0.7
Table 14 continued

Member/alternative

Attribute

\begin{tabular}{|c|c|c|c|c|c|c|}
\hline & $l_{3}$ & 0.2 & 0.6 & 0.3 & 0.2 & 0.5 \\
\hline \multirow{4}{*}{$e_{20}$} & $l_{4}$ & 0.5 & 0.3 & 0.7 & 0.6 & 0.3 \\
\hline & $l_{1}$ & 0.2 & 0.9 & 0.3 & 0.4 & 0.3 \\
\hline & $l_{2}$ & 0.7 & 0.5 & 0.5 & 0.2 & 0.7 \\
\hline & $l_{3}$ & 0.4 & 0.4 & 0.5 & 0.5 & 0.6 \\
\hline \multirow{3}{*}{$e_{21}$} & $l_{4}$ & 0.2 & 0.1 & 0.3 & 0.1 & 0.7 \\
\hline & $l_{1}$ & 0.6 & 0.5 & 0.3 & 0.3 & 0.8 \\
\hline & $l_{2}$ & 0.6 & 0.4 & 0.1 & 0.7 & 0.6 \\
\hline \multirow{5}{*}{$e_{22}$} & $l_{3}$ & 0.5 & 0.8 & 0.5 & 0.2 & 0.3 \\
\hline & $l_{4}$ & 0.4 & 0.5 & 0.1 & 0.6 & 0.2 \\
\hline & $l_{1}$ & 0.5 & 0.5 & 0.7 & 0.3 & 0.9 \\
\hline & $l_{2}$ & 0.6 & 0.5 & 0.1 & 0.7 & 0.3 \\
\hline & $l_{3}$ & 0.5 & 0.8 & 0.2 & 0.2 & 0.3 \\
\hline \multirow{4}{*}{$e_{23}$} & $l_{4}$ & 0.4 & 0.5 & 0.3 & 0.6 & 0.2 \\
\hline & $l_{1}$ & 0.3 & 0.8 & 0.5 & 0.5 & 0.5 \\
\hline & $l_{2}$ & 0.8 & 0.9 & 0.7 & 0.1 & 0.5 \\
\hline & $l_{3}$ & 0.6 & 0.4 & 0.6 & 0.4 & 0.8 \\
\hline
\end{tabular}

$l_{4}$

$e_{24} \quad l_{1}$

$\begin{array}{lllll}0.2 & 0.1 & 0.1 & 0.1 & 0.7\end{array}$

$\begin{array}{lllll}0.2 & 0.6 & 0.5 & 0.5 & 0.1\end{array}$

$\begin{array}{lllll}0.8 & 0.9 & 0.6 & 0.2 & 0.5\end{array}$

$\begin{array}{lllll}0.6 & 0.4 & 0.5 & 0.4 & 0.7\end{array}$

$\begin{array}{lllll}0.2 & 0.3 & 0.2 & 0.1 & 0.5\end{array}$

$\begin{array}{lllll}0.6 & 0.5 & 0.3 & 0.1 & 0.8\end{array}$

$\begin{array}{lllll}0.6 & 0.4 & 0.2 & 0.7 & 0.5\end{array}$

$\begin{array}{lllll}0.4 & 0.9 & 0.5 & 0.1 & 0.3\end{array}$

$\begin{array}{lllll}0.4 & 0.5 & 0.1 & 0.6 & 0.2\end{array}$

$\begin{array}{lllll}0.5 & 0.4 & 0.7 & 0.2 & 0.4\end{array}$

$\begin{array}{lllll}0.4 & 0.6 & 0.9 & 0.2 & 0.1\end{array}$

$\begin{array}{lllll}0.6 & 0.2 & 0.3 & 0.3 & 0.6\end{array}$

$\begin{array}{lllll}0.9 & 0.2 & 0.6 & 0.9 & 0.4\end{array}$

$\begin{array}{lllll}0.5 & 0.2 & 0.3 & 0.3 & 0.6\end{array}$

$\begin{array}{lllll}0.9 & 0.3 & 0.6 & 0.9 & 0.6\end{array}$

$\begin{array}{lllll}0.5 & 0.9 & 0.5 & 0.2 & 0.6\end{array}$

$\begin{array}{lllll}0.5 & 0.1 & 0.6 & 0.1 & 0.1\end{array}$

$\begin{array}{llllll}0.8 & 0.8 & 0.3 & 0.7 & 0.2\end{array}$

$\begin{array}{lllll}0.7 & 0.1 & 0.7 & 0.5 & 0.2\end{array}$

$\begin{array}{lllll}0.3 & 0.1 & 0.5 & 0.2 & 0.6\end{array}$

$\begin{array}{llllll}0.6 & 0.3 & 0.7 & 0.6 & 0.3\end{array}$

$\begin{array}{lllll}0.6 & 0.4 & 0.8 & 0.2 & 0.6\end{array}$

$\begin{array}{lllll}0.6 & 0.4 & 0.9 & 0.2 & 0.1\end{array}$

$\begin{array}{lllll}0.5 & 0.2 & 0.3 & 0.3 & 0.6\end{array}$

$\begin{array}{lllll}0.9 & 0.2 & 0.6 & 0.9 & 0.4\end{array}$

$\begin{array}{lllll}0.6 & 0.2 & 0.2 & 0.3 & 0.7\end{array}$

$\begin{array}{lllll}0.8 & 0.2 & 0.6 & 0.9 & 0.4\end{array}$

$\begin{array}{lllll}0.4 & 0.8 & 0.5 & 0.1 & 0.6\end{array}$

$\begin{array}{lllll}0.5 & 0.1 & 0.6 & 0.1 & 0.2\end{array}$ 
Table 14 continued

Member/alternative

Attribute

$\begin{array}{lllllll}c_{1} & c_{2} & c_{3} & c_{4} & c_{5}\end{array}$

$\begin{array}{lllllll}e_{31} & l_{1} & 0.5 & 0.4 & 0.7 & 0.1 & 0.9\end{array}$

$\begin{array}{llllll}l_{2} & 0.6 & 0.5 & 0.1 & 0.7 & 0.2\end{array}$

$\begin{array}{llllll}l_{3} & 0.5 & 0.8 & 0.3 & 0.2 & 0.3\end{array}$

$\begin{array}{lllllll}l_{4} & 0.4 & 0.5 & 0.3 & 0.4 & 0.3\end{array}$

$\begin{array}{lllllll}e_{32} & l_{1} & 0.4 & 0.5 & 0.7 & 0.2 & 0.9\end{array}$

$\begin{array}{lllll}0.5 & 0.6 & 0.2 & 0.7 & 0.2\end{array}$

$\begin{array}{lllll}0.5 & 0.9 & 0.3 & 0.3 & 0.3\end{array}$

$\begin{array}{lllll}0.4 & 0.5 & 0.3 & 0.6 & 0.2\end{array}$

$\begin{array}{lllll}0.8 & 0.8 & 0.2 & 0.7 & 0.3\end{array}$

$e_{33} \quad l_{1}$

$\begin{array}{lllll}0.6 & 0.1 & 0.7 & 0.5 & 0.2\end{array}$

$\begin{array}{lllll}0.3 & 0.1 & 0.4 & 0.1 & 0.6\end{array}$

$\begin{array}{lllll}0.7 & 0.3 & 0.8 & 0.6 & 0.3\end{array}$

$\begin{array}{lllllll}l_{2} & 0.7 & 0.2 & 0.7 & 0.5 & 0.2\end{array}$

$\begin{array}{lllll}0.3 & 0.1 & 0.5 & 0.2 & 0.6\end{array}$

$\begin{array}{lllll}0.7 & 0.3 & 0.8 & 0.6 & 0.4\end{array}$

$\begin{array}{lllll}0.7 & 0.2 & 0.3 & 0.4 & 0.6\end{array}$

$\begin{array}{lllll}0.9 & 0.1 & 0.4 & 0.8 & 0.4\end{array}$

$\begin{array}{lllll}0.5 & 0.8 & 0.4 & 0.1 & 0.6\end{array}$

$\begin{array}{lllll}0.4 & 0.1 & 0.6 & 0.2 & 0.3\end{array}$

$e_{36} \quad l_{1}$

$\begin{array}{lllll}0.3 & 0.5 & 0.6 & 0.1 & 0.9\end{array}$

$\begin{array}{lllll}0.6 & 0.4 & 0.1 & 0.7 & 0.2\end{array}$

$\begin{array}{lllll}0.4 & 0.9 & 0.3 & 0.2 & 0.5\end{array}$

$\begin{array}{lllll}0.4 & 0.5 & 0.3 & 0.6 & 0.2\end{array}$

$\begin{array}{lllll}0.5 & 0.4 & 0.7 & 0.1 & 0.8\end{array}$

$\begin{array}{lllll}0.6 & 0.5 & 0.1 & 0.7 & 0.2\end{array}$

$\begin{array}{lllll}0.5 & 0.7 & 0.4 & 0.2 & 0.3\end{array}$

$\begin{array}{lllll}0.4 & 0.5 & 0.3 & 0.6 & 0.2\end{array}$

$\begin{array}{lllll}0.4 & 0.5 & 0.5 & 0.2 & 0.9\end{array}$

$\begin{array}{lllll}0.7 & 0.6 & 0.1 & 0.7 & 0.2\end{array}$

$\begin{array}{lllll}0.5 & 0.9 & 0.3 & 0.2 & 0.3\end{array}$

$\begin{array}{lllll}0.4 & 0.5 & 0.3 & 0.6 & 0.2\end{array}$

$\begin{array}{lllll}0.6 & 0.8 & 0.3 & 0.7 & 0.3\end{array}$

$\begin{array}{lllll}0.7 & 0.3 & 0.7 & 0.5 & 0.2\end{array}$

$\begin{array}{lllll}0.3 & 0.1 & 0.5 & 0.2 & 0.6\end{array}$

$\begin{array}{lllll}0.7 & 0.3 & 0.8 & 0.6 & 0.3\end{array}$

$\begin{array}{lllll}0.7 & 0.7 & 0.3 & 0.7 & 0.2\end{array}$

$\begin{array}{lllll}0.5 & 0.1 & 0.7 & 0.7 & 0.2\end{array}$

$\begin{array}{lllll}0.3 & 0.1 & 0.5 & 0.2 & 0.6\end{array}$

$\begin{array}{lllll}0.7 & 0.3 & 0.7 & 0.6 & 0.3\end{array}$

\section{Appendix 2: Each cluster's weight distribu-} tion

See Table 15, 16, 17, 18, 19 and 20.

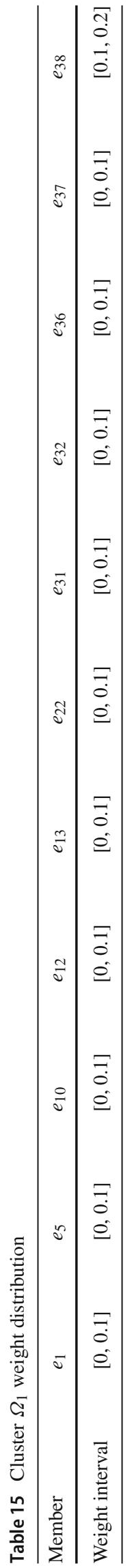


Table 16 Cluster $\Omega_{2}$ weight distribution

Table 17 Cluster $\Omega_{3}$ weight distribution

\begin{tabular}{llllll}
\hline Member & $e_{2}$ & $e_{9}$ & $e_{18}$ & $e_{21}$ & $e_{25}$ \\
\hline Weight interval & {$[0.5,0.6]$} & {$[0.1,0.2]$} & {$[0.1,0.2]$} & {$[0,0.1]$} & {$[0,0.1]$} \\
\hline
\end{tabular}

\begin{tabular}{llllllll}
\hline Member & $e_{3}$ & $e_{7}$ & $e_{11}$ & $e_{17}$ & $e_{27}$ & $e_{30}$ & $e_{35}$ \\
\hline Weight interval & {$[0,0.1]$} & {$[0,0.1]$} & {$[0,0.1]$} & {$[0,0.1]$} & {$[0.1,0.2]$} & {$[0.2,0.3]$} & {$[0.3,0.4]$} \\
\hline
\end{tabular}

Table 18 Cluster $\Omega_{4}$ weight distribution

\begin{tabular}{lllllllll}
\hline Member & $e_{4}$ & $e_{15}$ & $e_{19}$ & $e_{28}$ & $e_{33}$ & $e_{34}$ & $e_{39}$ & $e_{40}$ \\
\hline Weight interval & {$[0.2,0.3]$} & {$[0,0.1]$} & {$[0.1,0.2]$} & {$[0.1,0.2]$} & {$[0.3,0.4]$} & {$[0,0.1]$} & {$[0,0.1]$} & {$[0.1,0.2]$} \\
\hline
\end{tabular}

Table 19 Cluster $\Omega_{5}$ weight distribution

\begin{tabular}{llllll}
\hline Member & $e_{6}$ & $e_{14}$ & $e_{20}$ & $e_{23}$ & $e_{24}$ \\
\hline Weight interval & {$[0.1,0.2]$} & {$[0,0.1]$} & {$[0.5,0.6]$} & {$[0,0.1]$} & {$[0.2,0.3]$} \\
\hline
\end{tabular}

Table 20 Cluster $\Omega_{6}$ weight distribution

\begin{tabular}{lllll}
\hline Member & $e_{8}$ & $e_{16}$ & $e_{26}$ & $e_{29}$ \\
\hline Weight interval & {$[0,0.1]$} & {$[0.8,0.9]$} & {$[0,0.1]$} & {$[0,0.1]$} \\
\hline
\end{tabular}

\section{References}

Aven T (2015) Risk assessment and risk management: review of recent advances on their foundation. Eur J Oper Res 253(1):1-13

Bell DE (1982) Regret in decision making under uncertainty. Oper Res 30(5):961-981

Bin Z (2012) The research on decision-making participants' decisionmaking risk management of government invested projects. Zhejiang University, Hangzhou

Chengli Z, Yan C (2014) Portfolio selection based on relative entropy coherent risk measure. Syst Eng Theory Pract 3:648-655

Fasolo B, Costa CABE (2014) Tailoring value elicitation to decision makers' numeracy and fluency: expressing value judgments in numbers or words. Omega 44:83-90

Fleischhacker AJ, Fok PW (2015) On the relationship between entropy, demand uncertainty, and expected loss. Eur J Oper Res 245(2):623-628

Grechuk B, Zabarankin M (2015) Inverse portfolio problem with coherent risk measures. Eur J Oper Res 249(2):740-750

Junshan L (2007) Research on portfolio optimization based on risk measurement theory. Fudan University, Shanghai

Kahneman D, Tversky A (1979) Prospect theory: an analysis of decision under risk. Econometrica 47(2):263-291

Liu B, Shen Y, Chen X et al (2014) A complex multi-attribute largegroup PLS decision-making method in the interval-valued intuitionistic fuzzy environment. Appl Math Model 38(17-18):45124527

Pender J, Slowinski R, Artalejo J et al (2016) Risk measures and their application to staffing nonstationary service systems. Eur J Oper Res 254(1):113-126
The investigation Report on "7.23" special railway traffic accidents on Yong - Wen line[EB/OL] (2011). http://www.chinasafety.gov.cn/ newpage/Contents/Channel_21679/2011/1228/244874/content_ 244874.htm

The investigation report of dangerous goods warehouse major fire and explosion accident in Tianjin port " 8 - 12" Ruihai company[EB/OL] (2016). http://www.chinasafety.gov.cn/newpage/ newfiles/201600812baogao.pdf

The production safety accident investigation and report regulations. Chinese state council. the 493 order. http://www.chinasafety.gov. cn/2007-04/20/content_232858.htm

Wentao X, Dachao F (2011) The exploration of guiding strategy for network public opinion events. Chin Public Adm 12:24-28

Xinlei Z (2015) Research on information entropy methods in risk measure. Beijing Jiaotong University, Beijing

Xuanhua X, Xiaohong C, Hongwei W (2009) A kind of large group decision-making method oriented utility valued preference information. Control Decis 24(3):440-445

Xuanhua X, Minsai W, Xiaohong C (2014) Multi-attribute \& multistage large group decision-making method for preference conflict optimization. J Syst Eng 29(1):48-55

Yager RR, Alajlan N (2016) Some issues on the OWA aggregation with importance weighted arguments. Knowl Based Syst 100:89-96

Ye W, Luo K, Liu X (2017) Time-varying quantile association regression model with applications to financial contagion and VaR. Eur J Oper Res 256(3):1015-1028

Zhanfeng C (2012) Strengthening and perfecting the construction of risk evaluation mechanism of administrative decision. Adm Reform 9:70-74

Publisher's Note Springer Nature remains neutral with regard to jurisdictional claims in published maps and institutional affiliations. 